\title{
円形ケーシングを用いた極低比速度遠心ポンプの性能*
}

\author{
香 川修 作*1, 黒 川 淳 一*2 \\ 松井純*2, 崔永 都*2

\section{Performances of Very Low Specific Speed Centrifugal Pump with Circular Casing}

\author{
Shusaku KAGAWA, Junichi KUROKAWA*3, \\ Jun MATSUI and Young-Do CHOI \\ ${ }^{* 3}$ Department of Engineering, Yokohama National University, \\ 79-5 Tokiwadai, Hodogaya-ku, Yokohama-shi, Kanagawa, 240-8501 Japan
}

\begin{abstract}
Efficiency of a centrifugal pump is known to drop rapidly with a decrease of specific speed $n_{s}$ in the range of $n_{s} \leq 100$. However, below $n_{s}=60\left[\mathrm{~m}, \mathrm{~m}^{3} / \mathrm{min}, \mathrm{min}^{-1}\right]$, the pump efficiency is not yet clear, and the spiral angle of volute casing becomes too small to manufacture. To solve this problem, a circular casing is considered appropriate in the very low $n_{s}$ range. The present study is aimed to reveal the relation between pump efficiecy and a specific speed in the range of $n_{s} \leq 60$, when a circular casing is used. The results show that a circular casing gives higher efficiency than a spiral casing, and that radial thrust is considerably small in both casings compared with that of ordinary specific speed pump.
\end{abstract}

Key Words : Turbomachinary, Fluid Machinery, Pump, Very Low Specific Speed, Matching Performance, Circular Casing

\section{1.はじめに}

近年遠心ポンプの小型高速化に伴って, 低流量・高 揚程を特徵とする比速度 $n_{s}<100\left[\mathrm{~m}, \mathrm{~m}^{3} / \mathrm{min}, \mathrm{min}^{-1}\right]$ （形式数 $K<0.244 ）$ の極低比速度領域での性能につい て関心が高まっている.しかし，遠心ポンプの効率は 比速度の低下とともに低下すること豆が知られている. 著者らは極低比速度領域でのポンプ性能について研究 し, $n_{s}=60$ 付近で羽根車・ケーシング諸元が性能に及 ぼす影響を明らかにしてきた ${ }^{(2)(3)}$.さらに, 従来の常 識に反した漏れ流量の増加・背面粗さの増加による性 能向上法を示した ${ }^{(4)}$. また, 極低比速度領域では楴切 点付近に右上がり不安定性能が生じ易い( ${ }^{(5)}$ た, 右上 がり性能の生じる可能性が少ないセミオープン羽根車 を採用し，その内部流れや性能を検討してきた ${ }^{(6)}$. ま た, 最近ではセミオープン羽根車に対し最適化設計法 を用いて，小形低比速度ポンプの効率向上を実現した

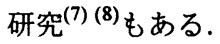

これらの研究では全て渦巻ケーシングを使用してい る. しかし, 極低比速度領域で通常の設計法 ${ }^{(1)(9)}$ を用 いると渦巻きの巻き角 $\gamma$ が著しく小さくなる. そのた

* 原稿受付 2005 年 1 月 14 日.

${ }^{* 1}$ 学生員, 横浜国立大学工学府システム統合工学専攻.

*2 正員, 横浜国立大学工学部工学研究院 ( 保土ヶ谷区常盤台 79-5).

E-mail : kuro@mach.me.ynu.ac.jp
め，鋳物で製作すると寸法管理が難しいことや内面を 水力学的滑面にすることが難しいことなどから，機械 加工が容易な円形ケーシングが適していると考えられ る.しかし，遠心ポンプに円形ケーシングを適用した 研究は少なく, 設計点においても流れが軸対称となら ない可能性があり半径スラストや振動などの問題が予 想される.

一方, 遠心ポンプの最高効率点は羽根車性能とケー シング性能の交点, いわゆるマッチング点で決定され ることを, Worster は理論的かつ実験的に明らかにし ている(10). しかし, 極低比速度領域では, ポンプの最 高効率点は羽根車の設計点よりもかなり大流量側に移

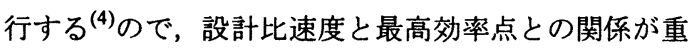
要となる.そこで, 著者の 1 人はポンプ性能に及ぼす 影響の大きい舌部寸法を考慮したマッチング点予測法 を提案し， $n_{s}=114$ のポンプを用いて舌部断面積によ り最高効率点流量が決まることを示した ${ }^{(5)}$ が，さらに 比速度の低い領域では, 舌部の影響が大変大きくなる ので, マッチング点の予測精度が低下する.

以上の背景から, 本研究では円形ケーシングを用い て, $n_{s} \leq 60$ の範囲を対象として羽根車とのマッチン グ性能および, 最高効率と比速度の関係を実験的に検 討する. 


\section{2.おもな記号}

\begin{tabular}{|c|c|c|}
\hline$A$ & : & 断面積 $\left[\mathrm{m}^{2}\right]$ \\
\hline$b$ & $:$ & 流路幅 [ m ] \\
\hline$n_{s}$ & : & 比速度 $\left[\mathrm{m}, \mathrm{m}^{3} / \mathrm{min}, \mathrm{min}^{-1}\right]$ \\
\hline$n_{s l}$ & : & 局所比速度 $\left[\mathrm{m}, \mathrm{m}^{3} / \mathrm{min}, \mathrm{min}^{-1}\right]$ \\
\hline$p$ & : & 圧力 [ Pa ] \\
\hline$r$ & : & 半径 [ m ] \\
\hline$u$ & : & 羽根車周速度 [ m/s ] \\
\hline$Z$ & : & 羽根枚数 \\
\hline$\beta$ & : & 羽根角度 [ํ] \\
\hline$\rho$ & : & 流体の密度 $\left[\mathrm{kg} / \mathrm{m}^{3}\right]$ \\
\hline$\phi$ & : & 流量係数 $=Q / A_{2} u_{2}(Q:$ 流量) \\
\hline$\psi$ & : & 揚程俰数 $=2 g H / u_{2}^{2}$ ( $H$ : 揚程) \\
\hline$\tau$ & . & $\begin{array}{l}\text { 軸動力係数 }=2 L / \rho A_{2} u_{2}^{3} \\
\text { ( } L: \text { 軸動力 })\end{array}$ \\
\hline$\eta$ & : & 効率 $=\rho g Q H / L$ \\
\hline$c_{p}$ & : & 圧力係数 $=2\left(p-p_{s}\right) /\left(\rho u_{2}^{2}\right)$ \\
\hline$c_{F}$ & : & $\begin{array}{l}\text { 半径スラスト係数 }=2 F_{r} /\left(\rho A_{2} u_{2}^{2}\right) \\
\left(F_{r} \text { 半径スラスト) }\right.\end{array}$ \\
\hline
\end{tabular}

\section{添 字}

2,3

$\mathbf{s}, \mathbf{v}$

D.P., M.P., BEP

\footnotetext{
羽根車出ロ, ケーシング 吸込口, 舌部

設計点, マッチング点, 最高効率点
}

\section{3. 極低比速度ポンプの設計指針}

極低比速度ポンプを従来の設計法(1) (9)に従って設計 すると, 羽根車出口幅 $b_{2}$ が著しく小さくなり製作限 界を越えてしまう。.また, 渦巻きの巻き角 $\gamma$ も著しく 小さくなり寸法管理が難しくなる．したがって，極低 比速度領域では, 従来の設計法が適用できなくなり, 新しい設計指針の検討が必要となる. そこで, 極低比 速度ポンプの設計指針について以下に検討する.

ポンプの形式を代表する比速度を無次元数を用いて 表すと次のように書ける.

$$
n_{s}^{\prime}=n \frac{\sqrt{Q_{D . P .}}}{H_{D . P .}^{3 / 4}}=1727 \sqrt{\frac{b_{2}}{r_{2}}} \frac{\sqrt{\phi_{D . P .}}}{\psi_{D . P .}^{3 / 4}}
$$

したがって，極低比速度を実現するためには， $b_{2} / r_{2}$ をできるだけ小さくするか， $\phi_{D . P .}$ を小さく， $\psi_{D . P .}$ を大 きく選定する以外に方法はない.このうち，前者は製 作上から $b_{2} / r_{2} \geq 0.02$ 程度が限界となるので, 結局設 計点における無次元比速度 $\omega_{s}=\sqrt{\phi_{D . P .}} / \psi_{D . P .}^{3 / 4}$ をどこま で低く選定できるかにかかっている. 一方， $\phi_{D . P .}$ は羽 根車性能を表す $\psi_{\text {imp }}$ とケーシング性能を表す $\psi_{\text {vol }}$ の 交点として以下の式を解くことによって与えられる(5) ので, 極低比速度を実現するには, $\psi-\phi$ 平面で 2 式
の交点の $n_{s}$ ができるだけ小さくなるように羽根車お よびケーシング諸元を最適化すればよいことになる.

$$
\begin{array}{r}
\psi_{\text {imp }}=2\left(1-k-\phi / \eta_{v} \varepsilon_{2} \tan \beta_{2}\right) \\
\psi_{v o l}=4 \pi b_{2} \phi / b_{3} \ln \left(1+A_{v} / b_{3} r_{v}\right)
\end{array}
$$

ここで， $k$ はすべり係数 ${ }^{(11)}, \eta_{\nu}$ は体積効率, $\varepsilon_{2}$ は羽 根厚による流路の狭まり率, $r_{v}$ は舌部先端の半径であ る. 式 (3) は渦巻ケーシング断面が矩形かつケーシン グ内流れが自由渦であるとして求められたものである.

図 1 は, $b_{2} / r_{2}=0.04, b_{3} / b_{2}=4.0, Z=6$ として $\psi_{D . P .}$ - $\phi_{D . P .}$ 平面上に, $n_{s}$ 一定の曲線を示したもので ある. また, 図中には $\psi-\phi$ 平面上で $\psi_{i m p}$ と $\psi_{v o l}$ も 示し，その交点として与えられる設計点 $\left(\phi_{D . P .}, \psi_{D . P .}\right)$ を黒丸（11～(4)）で示してある. $\psi_{\text {imp }}$ および $\psi_{\text {vol }}$ に影 響を与える主な因子にはそれぞれ $\left(\beta_{2}, Z, b_{2}\right)$ および $\left(b_{3}, \gamma, A_{v}\right)$ があり，このうち羽根出口角 $\beta_{2}$ および舌 部断面積 $A_{v}$ の影響がとくに大きいので, 図中には $\beta_{2}$ が $30^{\circ}, 60^{\circ}, 90^{\circ}$ の $\psi_{\text {imp }}$ 曲線および $A_{v} / A_{2}=0.05$ およ びその $1 / 2$ の值にしたときの $\psi_{v o l}$ 曲線を示している. 同図より $\beta_{2}$ を変化させても， $\psi_{i m p}$ および $\psi_{v o l}$ 曲線の 交点はNo.(1)（3) で示されるようにほとんど変化しな いが, $A_{v}$ を $1 / 2$ にすると(1) $\rightarrow$ (4) と大きく変化し, 設 計点の比速度は 55 程度 $\rightarrow 40$ 程度に大幅に変化する.

以上より極低比速度を実現するには, 羽根車設計諸 元ではなく $A_{v}$ を変化させることによって達成可能で あることがわかる. なお， $n_{s}$ は全揚程を用いて定義さ れるので, 図 1 の交点の比速度は, 正確には水力効率 を $\eta_{h}$ を考虑して $1 / \eta_{h}^{3 / 4}$ 倍する必要がある.

式 (3) で計算される $\psi_{v o l}$ は, 吐出スロートを矩形 として導かれた式(5)である. しかし, 比速度の低下と 共に $A_{v}$ が小さくなるのでケーシング内部, とくに舌 部付近の表面粗さが性能に与える影響が大きくなり, ケーシング内面および舌部から吐出口に至る断面は機

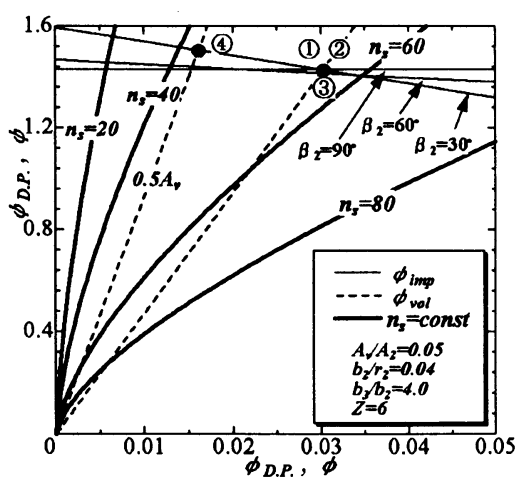

Fig. 1 Design chart of very low specific speed pump 
械加工ができる円形形状が適していると考えられる スロート部が，図 2 に示寸様な円形断面の場合の $\psi_{v o l}$ は, 羽根車出口 $r_{2}$ からケーシング半径 $r_{3}$ までの流れ を自由渦，かつスロート断面内で一様速度を仮定する と, 次式で計算される.

$$
\psi_{v o l}=2 \frac{v_{u 2}}{u_{2}}=4 \frac{\pi b_{2} r_{v}}{A_{v}} \phi
$$

\section{4. 実験装羁および实験方法}

\section{$4 \cdot 1$ 実験装置本研究で使用した横軸単段の極} 低比速度遠心ポンプを図 3 に示す，供試ケーシングと して円形および対数らせんをもつ渦巻ケーシングの 2 種類を使用し，その諸元を表 1 に示す. $r_{3}$ は円形ケー シングにおいては内半径を, 渦巻ケーシングでは基礎 円半径を表す. 円形ケーシングの $r_{3}$ は渦巻ケーシン グとケーシング内全流路面積が等しくなるように定め た. 本供試ケーシングは比速度 60 を目標として設計 したものであり， $A_{v}$ をほぼ等しくしているがスロー トの断面形状は異なり，それぞれ円形（円形ケーシン グ）および矩形（渦巻ケーシング）である. 渦巻ケー シングでは，巻き角 $\gamma$ が小さいことがわかる.どちら のケーシングも矩形断面を有し，内面には機械加工を 施し最大表面粗さを $\mathrm{R}_{\text {max }}=25 \mu \mathrm{m}$ に仕上げた。吐出ス ロート部は渦巻ケーシングでは鉡肌のまま, 円形ケー シングでは機械加工を施し表面粗さは $\mathrm{R}_{\max }=25 \mu \mathrm{m}$ に 仕上げてある.どちらのケーシングにもアクリル製の 吸込ケーシングがついており, 吸込口径 $100 \mathrm{~mm}$ で同じ である．吐出口径は異なり $40 \mathrm{~mm}$ (円形) $100 \mathrm{~mm}$ (渦 巻）であるが, 円形ケーシングには吐出口直後に拡大 管がついており，その前後で測定した揚程にはほとん ど差がないことを確認している.

供試羽根車としては円形ケーシングに対してマッチ ング性能を調べるため, 図 4 および表 2 に示すように $\beta_{2}$ および $Z$ の異なる 5 種類の 2 次元形状のクローズ ド羽根車を使用した。 これらは, 通常比速度での設計 法を極低比速度領域まで拡張したものである. Imp.A から Imp.D まではステンレス鋳物製であり製作精度

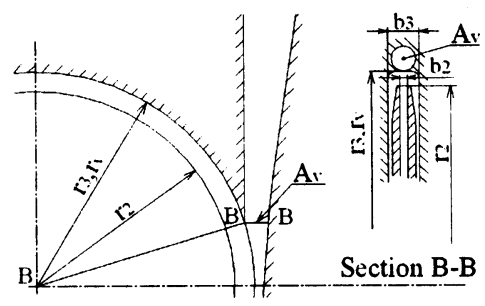

Fig. 2 Configuration of circular casing

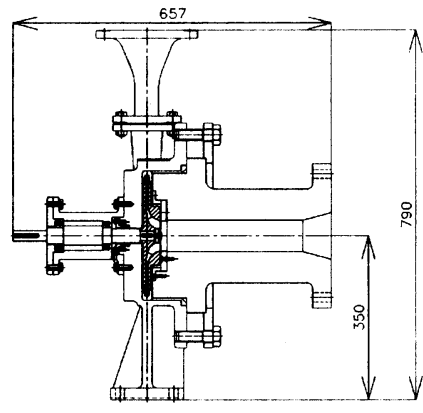

Fig. 3 Configuration of test centrifugal pump

Table 1 Dimension of casings tested

\begin{tabular}{c|c|c}
\hline & Circular casing & Spiral casing \\
\hline$b_{3}$ & 20.0 & 20.0 \\
$r_{3}$ & 138.5 & 133.3 \\
$\gamma$ & - & 0.68 \\
$A_{v}$ & 196.5 & 201.1 \\
\hline \multicolumn{2}{|c}{$b_{3}, r_{3}: \mathrm{mm} A_{v}: \mathrm{mm}^{2}$}
\end{tabular}
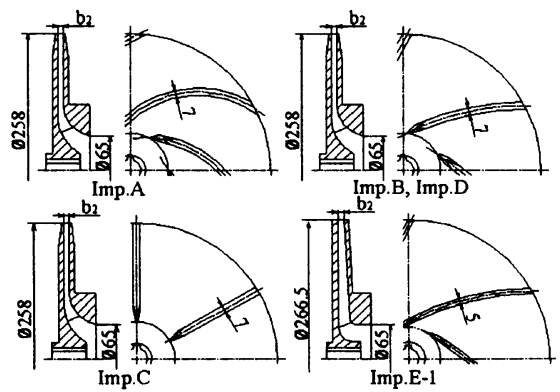

Fig. 4 Configuration of impellers tested

Table 2 Dimension of impellers tested

\begin{tabular}{c|c|c|c|c|c}
\hline Imp.No. & $\beta_{2}$ & $b_{2 \text { design }}$ & $b_{2 \text { meas. }}$ & $r_{2}$ & $\mathrm{Z}$ \\
\hline $\mathrm{A}$ & 30 & 5.0 & $5.0 \sim 5.8$ & 129 & 6 \\
$\mathrm{~B}$ & 60 & 5.0 & $4.7 \sim 5.7$ & 129 & 6 \\
$\mathrm{C}$ & 90 & 5.0 & $4.6 \sim 6.0$ & 129 & 6 \\
$\mathrm{D}$ & 60 & 5.0 & $5.6 \sim 6.8$ & 129 & 4 \\
$\mathrm{E}-2$ & 60 & 6.2 & 6.2 & 129 & 6 \\
\hline \multicolumn{6}{c}{$b_{2 \text { design }}, b_{2 \text { meas. }}, r_{2}: \mathrm{mm}$}
\end{tabular}

が低くならざるを得ないため, $b_{2}$ の設計值を $b_{2 d e s i g n}$

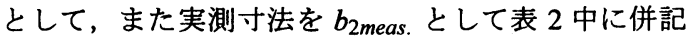
した. $b_{2}$ の寸法誤差の影響を検討するために, 新た に機械加工により正確に仕上げた Imp.E も実験した. Imp.E は流路表面が滑らかな上に, 流路断面積変化が できるだけ一様になる様に仕上げているので, 性能向 上が期待できる. また, 円形ケーシングに対しては性 能が従来から明らかではないので, Imp.E を用いて羽 根車外径切削による性能の変化を測定した. 羽根車外 径の変化を表 3 に示す. いずれの羽根車もトルク計 を介しインバータによる回転数制御をおこない， 3 相 


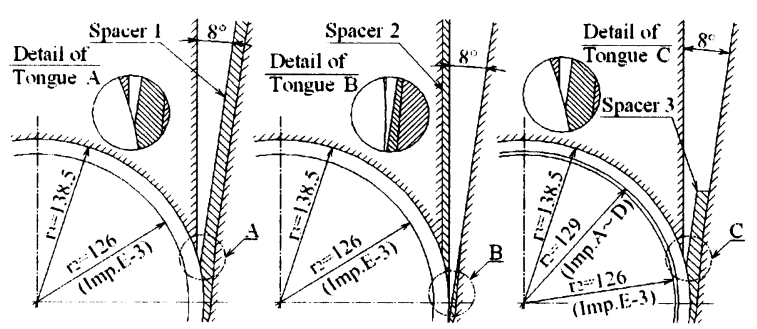

Fig. 5 Configuration of casing throat with spacer

Table 3 Dimension of impeller E for impeller cut test

\begin{tabular}{c|c|c|c}
\hline Imp.No. & $b_{2}$ & $r_{2}$ & $r_{3} / r_{2}$ \\
\hline E-1 & 6.0 & 132.3 & 1.05 \\
E-2 & 6.2 & 129 & 1.07 \\
E-3 & 6.3 & 126 & 1.10 \\
\hline \multicolumn{4}{c}{$b_{2}, r_{2}: \mathrm{mm}$}
\end{tabular}

Table 4 Variation of throat sectional area

\begin{tabular}{c|c|c|c}
\hline No. & $A_{v}$-I & $A_{v}$-II & $A_{v}$-III \\
\hline Sp.1 & 23.2 & 45.9 & 98.0 \\
Sp.2 & 29.6 & 45.9 & 96.2 \\
Sp.3 & 23.2 & 28.6 & - \\
\hline \multicolumn{2}{c}{$A_{v}: \mathrm{mm}^{2}$}
\end{tabular}

誘導電動機で駆動した. 羽根車周速にもとづくレイノ ルズ数は $R e=(2.6 \sim 2.9) \times 10^{6}$ である.

4.2 実験方法通常の比速度範囲において, 遠 心ポンプ比速度を変化させるには $b_{2}$ および $\gamma$ を変化 させるのが普通である. しかし, 極低比速度領域で比 速度を広範囲に変化させるためには，前章から $A_{v}$ を 変化させれば良いことが判明した. そこで, 図 5 に示 す 3 種類のスペーサを舌部に挿入し積極的に断面積を 変化させた. なお, 円形ケーシングと渦巻ケーシング の性能比較の結果, 円形ケーシングの方が極低比速度 領域で適していることが判明したので， $A_{v}$ の変化には 円形ケーシングを用いた. どのスペーサも $8^{\circ}$ の開き 角を持つようにした. Sp. 1 と Sp. 2 の比較から位置の 影響を検討し, Sp. 1 と Sp. 3 の比較から吐出スロート 形状の影響について検討する. スペーサ使用時の $A_{v}$ の実測值を表 4 に示す. 以下, Sp.1- $A_{v}$ II の表記は, ス ペーサ 1 で舌部断面積が $A_{v}$-II であることを表す.

\section{5. 円形ヶーシングの性能}

$5 \cdot 1$ 円形ケーシングと渦巻ケーシングの比較 図 6 に $\beta_{2}=60^{\circ}, Z=6$ の Imp.B を用いて, 円形ケーシン

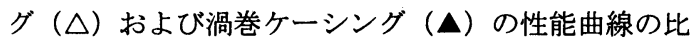
較を示す. 揚程は円形ケーシングの方が渦巻ケーシン グよりも全流量域で高い. 円形ケーシングではわずか に揚程の右上がり不安定性能が生じている. 軸動力に は全流量域でケーシングの差異がみられないこと，お よび同一流量において周方向圧力分布（後述図 7(a)）

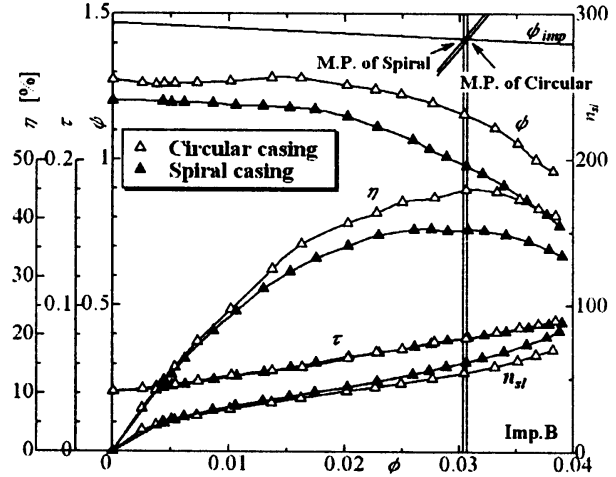

Fig. 6 Influence of casing type on pump peformances

が両ケーシングで, ほぼ同じ值を示すことから, 羽根 車内部および出口流れはケーシングの影響をあまり受 けないと考えられる. 効率は全流量域で円形ケーシン グの方が渦巻ケーシングに比較して高く, 最高効率の 差は約 7\%にも達する. 他の羽根車 (Imp.A 〜 Imp.D) でも同じ傾向がみられた.この効率の差は, 羽根車出 口から吐出口までのケーシング内の水力損失の違いが 原因と考えられる. また, 渦巻ケーシングでは式 (2), (3) の交点で, 円形ケーシングでは式 (2), (4) の交点で 計算される $\phi_{M . P .}$ は両ケーシングで最高効率点流量と 良好に一致する. 一方, $n_{s}$ に対する効率の変化でも円 形ケーシングの方が全局所比速度範囲で効率が高く, 両ケーシング共に目標通り $n_{s}=60$ 付近で最高効率を とる.

円形ケーシングを用いた場合の最大の問題点は, 設 計点においても羽根車出口流れが軸対称にならないこ とによる半径スラストの発生である.これを検討する ために，ケーシング内圧力の周方向変化を測定した. 図 7 (a)に Imp.B を用いて円形ケーシング（白丸）お よび渦巻ケーシング (黒丸) $の ~ r / r_{2}=1.0$ における $c_{p}$ の比較を示す. また, 圧力分布を周方向に面積積分し て得られる力を半径スラスト $F_{r}$ として，それを無次 元化した半径スラスト係数 $c_{F}$ を図 7 (b) に示し, 羽根 枚数の異なる Imp.D も合わせて示した.

図 7 (a) より, 両ケーシングともに舌部付近で多少 の変動がみられるものの，共に全流量域で周方向にほ ぼ均一な圧力分布になることがわかる. 図 7 (b) には 従来用いられている半径スラストの経験式 ${ }^{(1)}$ 示した が，極低比速度領域では実験值と傾向も大きさも全く 異り, 流量依存性が大変低く, また通常比速度と比較 しても半径スラストは著しく低い.このため, 極低比 速度では円形ケーシングを採用しても半径スラストは 問題とならない. 


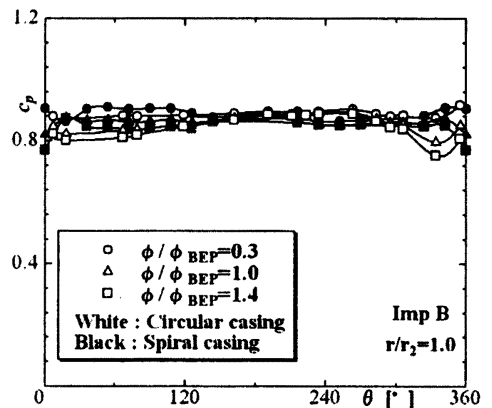

(a) Pressure distribution

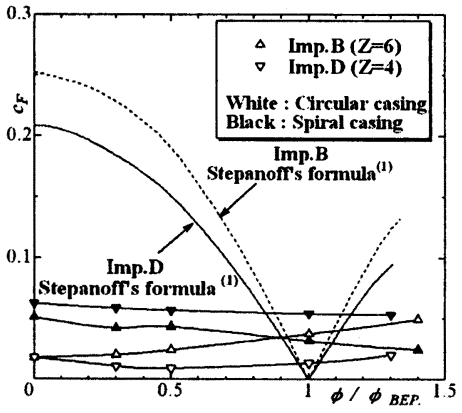

(b) Radial thrust

Fig. 7 Influence of casing type on casing wall static pressure and radial thrust

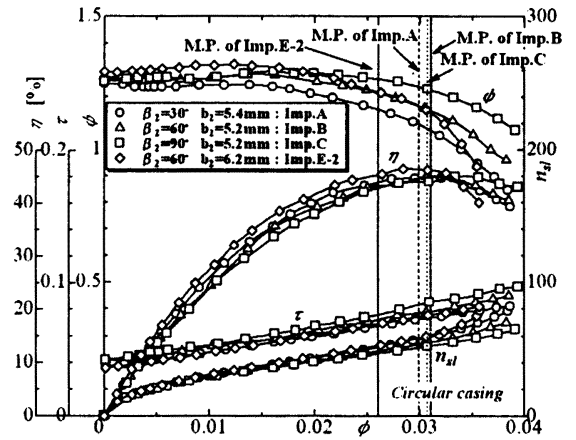

Fig. 8 Influence of impeller outlet angle

5.2 羽根出口角度の影㖕 図 8 に $Z=6$ に固定し て, $\beta_{2}$ が $30^{\circ}(\bigcirc), 60^{\circ}(\triangle), 90^{\circ}(\square)$ の性能曲線の 比較を示し， $b_{2}$ の製作誤差の影響を検討するため同じ 外径の Imp.E-2 (๖) の結果も併せて示した. 図 8 によ れば, 締切揚程は全羽根車でほぼ同一であり, 通常比 速度と同様に $\beta_{2}$ の増大に伴って揚程曲線のこう配が低 下するが，その差異は少ないこと，そして右上がり不 安定性能が $\beta_{2}$ の増大とともに多少生じやすくなるこ とがわかる. 軸動力の差もかなり小さい. 効率に関し ては，最高効率は $\eta_{\max }=44.9 \%$ (O)， $\eta_{\max }=45.1 \%$ $(\triangle), \eta_{\max }=45.1 \%(\square), \eta_{\max }=46.6 \%(\diamond)$ と約 $\pm 1 \%$ 範囲にとどまっている. なお，いずれの羽根 車も最高効率点の比速度はほぼ 60 であった。

一方，性能に及ぼす寸法誤差の影響は，正確につく られた Imp.E-2（৩）とほぼ同一諸元を持ち製作誤差 の大きいステンレス鋳物製の Imp.B $(\triangle)$ の比較から, 内面を滑らかに仕上げた Imp.E-2 の方が揚程が多少高 く, 軸動力に大差がないことから効率は多少高くなる が，その差は必ずしも大きくはない．極低比速度羽根 車は, 流路幅が大変狭いため, 表面粗さの影響が特に 大きいと予想されたにも拘らず，最高効率があまり改 善されなかったことから, 羽根車の水力損失はポンプ

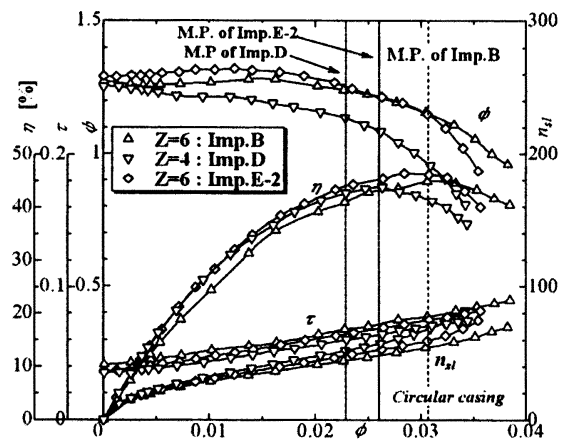

Fig. 9 Influence of impeller number

効率にあまり影響を与えないことが判明した．これら のことから，最高効率に及ぼす $\beta_{2}$ および $b_{2}$ の製作誤 差や内面粗さの影響は少ないといえる. また, 最高効 率流量は, 計算より求めたマッチング点とどの羽根車 でも良好に一致している.

5.3 羽根枚数の影橥 図 9 に $\beta_{2}=60^{\circ}$ に固定し て, $Z=6(\triangle)$ および $Z=4(\nabla)$ の性能曲線の比較 を示し, 羽根車内面を滑らかにした Imp.E-2 の結果も 併記した．揚程は，通常比速度と同様に羽根枚数を减 らすと右上がり不安定性能が生じにくくなるが，最高 効率が多少低下する. 羽根枚数が多い方が揚程および 軸動力ともに，ほぼ全流量域で大きくなっており，す べりの低下による理論揚程の増大が原因であることを 示している. 最高効率流量の位置は, 計算されたマッ チング点と比較的良好に一致している，最高効率は Imp.D で $\eta_{\max }=44.0 \%$ であり, Imp.B およびImp.E-2 と比較しても約 $\pm 1 \%$ 範囲にとどまっており最高効 率に及ぼす Z の影響も小さい. 図示していないが渦巻 ケーシングを用いた場合の $\beta_{2}$ および $Z$ の影響も，上 記の結果と同様であった，以上より，極低比速度では 最高効率に及ぼす羽根車諸元の影響は少ないと結論さ れる。 


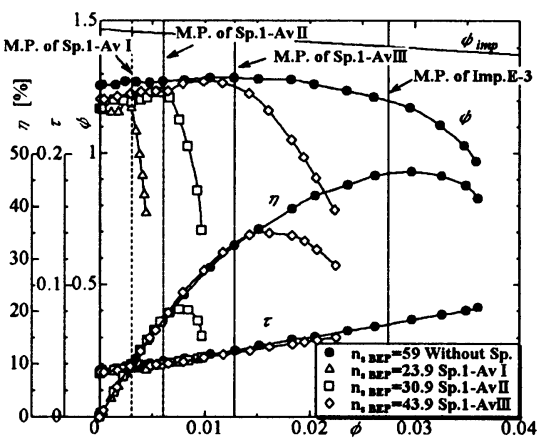

(a) Performance curves

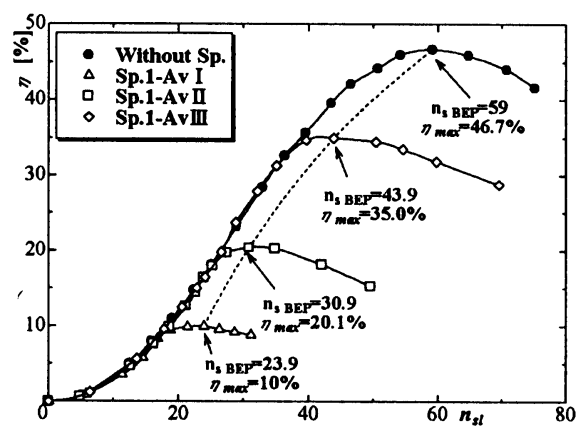

(b) Efficiency vs. local specific speed

Fig. 10 Influence of volute throat sectional area $A_{v}$ (Sp.1)

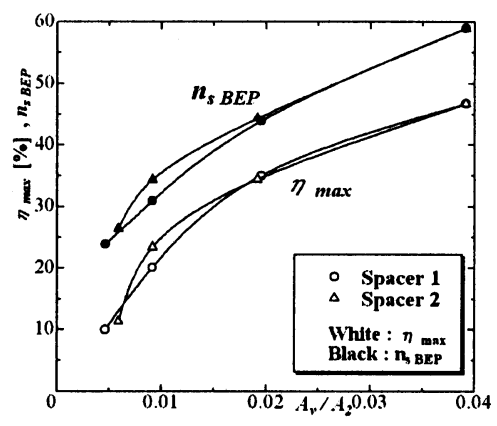

(a) $A_{v} / A_{2}$ vs. $\eta_{\max }, n_{s B E P}$

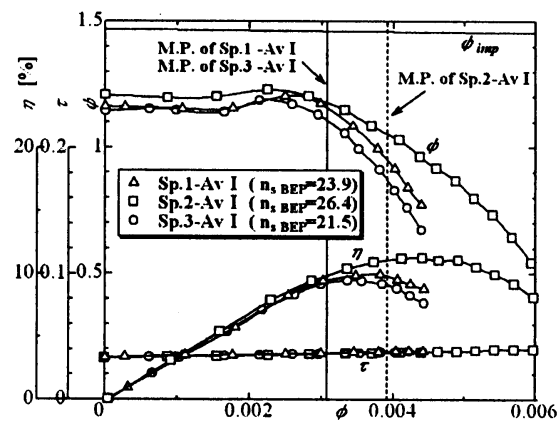

(b) Influence of spacer type

Fig. 11 Influence of spacer on pump performance

\section{6. 比速度と最高効率の関係}

\section{1 円形ケーシングの舌部断面稓変化と比速度} 図 10 (a) にSp. 1 を用いて舌部断面積を表 4 のよう に積極的に変化させたときの性能曲線を, また図 10 (b) には局所比速度に対する効率の变化を示す. 図中 には, 最高効率点比速度の数值を記入してある. 供試 羽根車には，円形ケーシングと比較的マッチングがよ い(後述) Imp.E-3 と $r_{3} / r_{2}=1.10$ の円形ケーシング を採用した. 図から $A_{v}$ の縮小に伴って $\phi_{B E P}$ が急激に 低下し, これに伴って最高効率点比速度 $n_{S B E P}$ も急低 下していくことがわかる. 興味深いのは, 効率曲線が 一本に重なり， $A_{v}$ の低下と共に，この曲線から外れる 点が低流量側に移行していくことである. また，揚程 の右上がり不安定性能については $A_{\nu}$ の縮小に伴って 顕著になっていく，スペーサにより軸動力は殆んど変 化しないことから，羽根車内部流れはあまり変化しな いことがわかる. したがって, 最高効率点よりも大流 量域における揚程の急低下はスペーサを挿入したこと による舌部スロートでの摩擦損失の急増大によるもの と考えられる. 計算でえられたマッチング点はいずれ
の場合とも，最高効率点よりも若干低流量側にずれて いるが，計測值と比較的良好に一致している.

図 10 (b) から， $n_{s l}$ に対する効率曲線は $n_{s B E P}$ で山形 の特性を持ち，スペーサ挿入前の $n_{s l}$ に対する効率曲 線（の印）を超えることはなく，各舌部面積における 最高効率は点線で示すように $n_{s}=60$ のポンプの効率 よりも $5 \%$ 程度も低くなる.このことは, 極低比速度 ポンプを設計する際, 舌部面積を小さくするよりも， むしろ比速度の大きなポンプを部分流量で運転した方 が高い効率を達成し得ることを示している.

6.2 スペーサ位㬅および形状の影霓 $A_{\nu}$ の変化 により極低比速度を達成できることが判明したが， ス ペーサで舌部断面積を変化させる場合，スペーサの挿 入位置や形状が問題となる. そこで, 図 11 (a)に Sp. 1 と Sp. 2 による性能の比較を示す. 横軸に $A_{v}$ と $A_{2}$ の比をとり, 縋軸に $\eta_{\max }$ および $n_{S B E P}$ を示している. また, 図 $11(\mathrm{~b})$ には, $n_{s}=25$ の場合について, 全ス ペーサに対する性能曲線の比較を示す. 辞部断面積が 多少異なるため, 同一比速度における比較はできない が, 全体的な傾向は把握できる. 図 11 (a) より舌部断 


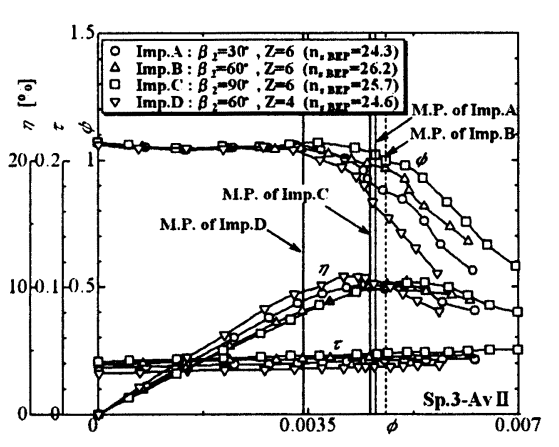

Fig. 12 Influence of impeller design parameter (Sp.3)

面積の減少とともに $\eta_{\max }$ も $n_{s B E P}$ も急低下し, とく に $A_{v} / A_{2} \leq 0.01$, 比速度 40 以下でその傾向が著しい こと, そしてスペーサの位置の差異による影響は比較 的小さいことがわかる. 興味深いのは, $n_{S B E P}$ の低下 と $\eta_{\max }$ の低下がほぼ同じ傾向をもつことであり，遠 心ポンプの効率はとくに比速度が低い領域では低すぎ て実用的ではなくなるが, 図 11 (a) は極低比速度ポン プを設計する際の性能に対する目安を与える.

一方，図 11 (b)によれば，スペーサ形状により揚程 および効率曲線に差異がみられるが，図 11 (a)による と比速度 25 付近では， $A_{\nu}$ のわずかな差により $\eta_{\max }$ お よび $n_{S B E P}$ が大幅に変化することから図 11 (b) の性能 の差異は $n_{s}$ の差に基づくものと判断される. 最高効率 を比較すると, Sp. 1, 2,3 でそれぞれ， $\eta_{\max }=10.0 \%$, $\eta_{\max }=11.5 \%, \eta_{\max }=9.5 \%$ と低いが, これらの差は 小さく，またSp. 3 における流路の急拡大の影響も比 較的小さいといえる. 以上のことから，スペーサの位 置や形状に関しては最高効率にはあまり影響を及ぼさ ないと判断される.

\section{7. 比速度 25 付近のポンプ性能}

従来から比速度の著しく低い領域においては, 遠心 ポンプの性能に関するデータは皆無に近い，そこで, 本研究で得られた最も低い $n_{s}=25$ 付近において羽根 車設計諸元がポンプ性能に及ぼす影響を検討する.

図 12 に, Sp. 3 を使用し舌部断面積を $A_{v}$-II, $Z=6$ に固定して $\beta_{2}$ が $30^{\circ}(\bigcirc) ， 60^{\circ}(\triangle), 90^{\circ}(\square)$ の 羽根車および, $\beta_{2}=60^{\circ}$ に固定して羽根枚数が $Z=6$ $(\triangle), Z=4(\nabla)$ の性能曲線の比較を示す. $\beta_{2}$ の差 異は, 理論揚程曲線に大きな差異を生じる䇢であるが, 図 12 によれば, 締切点から最高効率点までの揚程曲線 はあまり差異がない，このことから，スペーサの挿入 による舌部での水力損失が著しく大きいため, $\beta_{2}$ によ る揚程曲線の差異は比較的小さいことがわかる. 一方,
低流量域での揚程は羽根枚数によらずほぼ同じになっ ている. 軸動力は羽根枚数が多い方が全流量域でほぼ 一様に大きくなっており，すべりの低下による理論揚 程の増大が原因と考えられる. 効率曲線もあまり変化 せず，最高効率は $\eta_{\max }=10.2 \%(\bigcirc), \eta_{\max }=10.4 \%$ $(\triangle), \eta_{\max }=10.3 \%(\square), \eta_{\max }=10.8 \%(\nabla)$ と大 差がなく最高効率に及ぼす $\beta_{2}$ および $Z$ の影響は少な い. また, 式 (2), (4) で計算される $\phi_{M . P .}$ は著しく比速 度の低い $n_{s}=25$ 付近に対しても測定值と良好に一致 する. なお, 図示していないが周方向の圧力分布およ び半径スラストは図 7 とほぼ同様であった。

\section{8. 円形ケーシングの最適寸法と羽根車外径切削}

前節の結果から，極低比速度では効率は比速度とと もに大きく変化することが明らかとなった. 極低比速 度領域ではケーシング寸法の変化は比速度を変化させ るので, 図 11 (a)に示した様に最高効率も大きく変化 することになる. そこで, ケーシング寸法が最高効率 に及ぼす影響を以下に検討する. なお，式(1) (4)に よれば, ケーシング寸法を変化させても $r_{v} b_{2} / A_{\nu}$ およ び $b_{2} / r_{2}$ が一定に保たれる限り, マッチング点の比速 度は変化しないので, ポンプの最高効率はあまり変化 しないと予想される. しかし, 従来からケーシングの 最適化はポンプ効率が高くなるような寸法の探究とし て行われ， $n_{s}$ の変化は考虑されないことが多いので, ここでも最高効率の向上を判定基準とする.

式(1) (4)によれば, 同一羽根車に対してケーシン グ半径 $r_{v} \rightarrow$ 小, あるいは $A_{v} \rightarrow$ 大とすると, $\psi_{v o l}$ と $\psi_{i m p}$ の交点として与えられる $\phi_{M . P .} \rightarrow$ 大, $\psi_{M . P .} \rightarrow$ 小 となり，比速度が増大するため効率は向上する. 逆に, 同一ケーシングに対して羽根車寸法 $r_{2} \rightarrow$ 小としても, $\psi_{v o l}$ と $\psi_{i m p}$ は変化しないが式(1)の比速度を増加させ るので効率は向上する.

以上のことは, $\Delta r=r_{3}-r_{2}$ に注目すると, 同一羽 根車に対しては $\Delta r \rightarrow$ 小の方が効率が向上するが, 同 一ケーシングに対しては $\Delta r \rightarrow$ 大の方が効率が向上す るという，一見矛盾するような結果を与える. そこで， 上記の推論を確認するために, Imp.E および円形ケー シングを用いて羽根車外径 $r_{2}$ を切削していったとき の性能変化を測定した. 外径切削は生産現場でしばし ば採用されるので, 実用性を考虑して, 性能曲線の変 化を有次元で図 13 (a)に，また局所比速度に対する効 率の変化を図 13 (b) に示す. 図 13 (a)によれば, 外径 切削とともに揚程及び軸動力が大幅に低下し, その結 果効率は向上している.これは, 図 13 (b)によれば, 最高効率点が高比速度側に移行したために最高効率が 


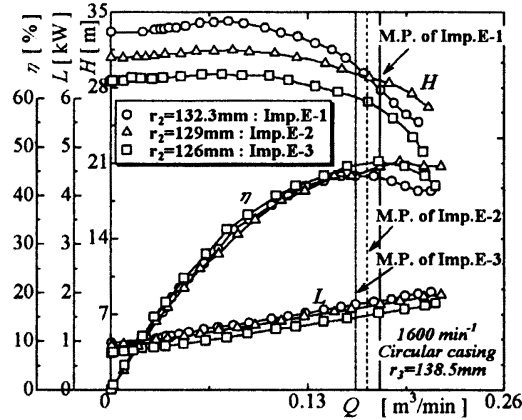

(a) Performance curves

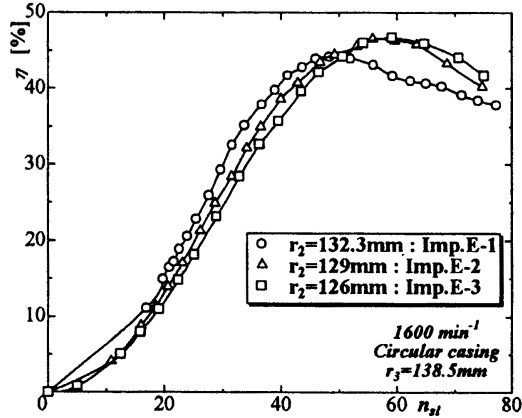

(b) Efficiency vs. local specific speed

Fig. 13 Influence of impeller cut on pump performance

大きくなったものと解棌され, 前記の推論が裏付けら れる. 以上のことから, 円形ケーシングの最適化は最 高効率点の比速度を增大させる様に行えばよいことが 結論される.なお, 図 13 (b)において興味深いことは, $n_{s} \leq 50$ では, $r_{2}$ の大きい方が局所効率が高くなって いることであり，例えば $n_{s l}=30$ 程度では Imp.E-3 よ りも Imp.E-1 が約 7\%も効率が高い.このことは, 先 ず羽根車を最適化 ${ }^{(2)}(7)$ した上でケーシングの最適化を 図ることにより，極低比速度における効率の改善が図 れることを示唆している.

\section{9. 結 論}

円形ケーシングを用い，設計諸元の異なる 5 種類の 羽根車と組み合わせて性能を測定し, 極低比速度領域 でのマッチングについて検討した. とくに, 従来から 明らかでない比速度の著しく低い領域でのポンプ性能 および习习习根車諸元の影響を実験的に検討した. 得られ た結論は以下のようになる.

(1) 渦巻ケーシングよりも円形ケーシングの方が最 高効率が高く，極低比速度領域に適している。

(2) 舌部断面積を縮小することにより, 最高効率点 を著しく低流量側に移行させ，極低比速度ポンプを実 現することができるが，舌部断面積を縮小しないポン プを部分流量域で運転した場合よりも最高効率が約 5\%程度低下寸る.

(3) 極低比速度領域では, 圧力分布は周方向にほほ 均一となり半径スラストはほとんど問題にならない.

(4) 最高効率に及ぼす羽根車諸元・羽根車出口幅の 製作誤差の影響は比較的小さい.

(5) 極低比速度ポンプの最高効率は, 比速度にほぼ比 例して低下し， $n_{s}<40$ ではその低下がとくに大きい.

(6) 羽根車の外径切削および円形ケーシングの縮小
はいずれも最高効率を向上させるが，最高効率点にお ける比速度も増加する.

(7) 本論文で示したケーシング性能 $\psi_{v o l}$ によりマッ チング点は比較的良好に予測できる.

\section{碀辞}

実験装㯰をご提供いただいた日機装 (株) 筒井俊明 氏・服部雅威氏，貴重なご助言をいただいた (株) タッ ノメカトロニクス松本一成氏に深甚な謝意を記す。

\section{文献}

(1) Stepanoff, A. J., Centrifugal and Axial Flow Pumps, 2nd ed., (1957), 76, John Wiley and Sons.

（2）松本・ほか 5 名, 極低比速度羽根車の性能, ターボ機械, 25-7, (1997), 337-345.

(3) 松本・ほか 4 名, 極低比速度渦巻きポンプの最適形状の 探究, 機論, 66-644, B(2000), 1132-1139.

(4) 松本・ほか 3 名, 極低比速度ポンプの性能向上と円板 摩擦・漏れの特異な挙動, 機論, 65-640, B(1999), 40274032.

(5) 黒川・ほか 2 名, 低比速度うず巻ポンプの性能, ターボ 機械, 18-5, (1990), 300-307.

(6) 崔 • ほか 4 名, 極低比速度セミオープン羽根車の内部流 れに関する研究, ターボ機械, 31-1, (2003), 43-52.

(7) 曹 - ほか 4 名, 小形低比速度ポンプの高効率 - 高信頼 性設計に関する実験的研究, ターボ機械, 31-10, (2003), 598-604.

（8）曹・ほか 3 名, 高効率・高信頼性・高温直流ブラシレス キャンドモータの開発, 第 51 回ターボ機械協会総会講 演会論文集, (2004-5), 7-12

(9) Pfleiderer, C., Die Kreiselpumpen für Flübikeiten und Gase 5 Aufl., (1961), 348, Springer- Verlag.

(10) Worster, R. C., The Flow in Volutes and its Effect on Centrifugal Pump Performance, Proc. IME., 177-31, (1963), 843-875

(11) Wiesner, F. J., A Review of Slip Factors for Centrifugal Impellers, Trans.ASME, 89-4, Ser.A(1967), 558-572 